\title{
Spinal Anaesthesia and General Anaesthesia for Laparoscopic Cholecystectomy: Study in a Private Hospital, Dhaka, Bangladesh
} Dr. Mohammad Mostafizur Rahman ${ }^{1 *}$, Dr. Jannatul Ferdous ${ }^{2}$

${ }^{1}$ Assistant Professor, Department of Anesthesia, Shaheed Monsur Ali Medical College Hospital, Dhaka, Bangladesh

${ }^{2}$ Associate Professor, Department of Gynae \& Obstetric, Ashiyan Medical College Hospital, Barua Khilkhet, Dhaka, Bangladesh

DOI: $10.36347 /$ sjams.2020.v08i11.018

| Received: 29.10.2020 | Accepted: 11.11.2020 | Published: 14.11.2020

*Corresponding author: Dr. Mohammad Mostafizur Rahman

Abstract

Original Research Article

Introduction: Laparoscopic cholecystectomy is an insignificantly offensive surgical procedure for the elimination of a diseased gallbladder. LC has become the gold standard for the surgical treatment of symptomatic cholelithiasis and has gained worldwide acceptance. It is a negligibly invasive procedure with a considerably shorter hospital stay and a earlier recovery compared with the classical open cholecystectomy. Aim of the study: The aim of our study was to compare between Spinal Anaesthesia and General Anaesthesia for laparoscopic cholecystectomy in healthy patients. Material \& Methods: This comparative clinical study was conducted in the Department of Anesthesia, Ashiyan Medical College Hospital, Barua Khilkhet, Dhaka, Bangladesh during the period from January 2017 to December 2017. The aim of our study was to compare between Spinal Anaesthesia and General Anaesthesia for laparoscopic cholecystectomy in healthy patients. A total of 120 patients aged between 18-65 years of both sex with ASA Grade status I and II undergoing elective laparoscopic Cholecystectomy were selected for the study. After taking written informed consent from the study participants, we were elected 120 study subjects and divided into two groups; Group I $(n=60)$ received General Anaesthesia. And Group II $(n=60)$ received Spinal Anaesthesia. Elective laparoscopic Cholecystectomy procedure was taken. Results: In this study majority patients (70\% and 63\% in Group I and Group II respectively) were male and mean age was 36.67 in Group I, 34.58 in Group II. Mean operative time (minutes) were 66.03 in Group I, 66.63 in Group II. Average hospital stay was 48.33 hours in Group I and 36.53 hours in Group II. Conclusion: Spinal Anaesthesia was observed to be better safety and sufficiency in patients of good health in the present study.

Key words: Anaesthesia, Spinal Anaesthesia, General Anaesthesia, Laparoscopic cholecystectomy.

Copyright $\odot 2020$ The Author(s): This is an open-access article distributed under the terms of the Creative Commons Attribution 4.0 International License (CC BY-NC 4.0) which permits unrestricted use, distribution, and reproduction in any medium for non-commercial use provided the original author and source are credited.

\section{INTRODUCTION}

Laparoscopic cholecystectomy has become the gold standard for the surgical treatment of symptomatic cholelithiasis and has gained worldwide acceptance [1]. It is a negligibly invasive procedure with a considerably shorter hospital stay and an earlier recovery compared with the classical open cholecystectomy [2]. General anesthesia (GA) as the most appropriate technique for laparoscopic procedures is a concept of the past. There is rising evidence suggesting that spinal anesthesia has an important role to play in the care of patients undergoing laparoscopic procedures. LC might be related to postoperative pain, nausea and vomiting (PONV) and is usually done under general anaesthesia (GA). Spinal anesthesia (SA) is a commonly used anaesthetic technique that has a very good safety profile. SA has several advantages over GA. These compensations comprise of the patients' being awake and concerned with at the end of the procedure, fewer postoperative pain, and the ability to ambulate formerly than patients getting general anesthesia. General anaesthesia (GA) remnants the choice for the mainstream of open abdominal surgical techniques and spinal anaesthesia is preferred for patients who are at high risks under general anaesthesia. For last few years, the trend has been doing almost all the open abdominal surgeries, including surgery of the upper abdominal surgeries, surgery of the upper abdominal organs like the stomach, and hepatobiliary system under spinal anaesthesia (SA). Evidences until about 5years ago recommended only GA as the anaesthetic choice for abdominal laparoscopic surgery being implemented with select patients under spinal or epidural anaesthesia have started to look. Spinal anesthesia has been effectively used for laparoscopic cholecystectomy in patients unhealthy to have the method under general anesthesia but has not been experienced in healthy patients in whom any recognized danger would be hypothetically much lower. For the anesthetist, it is 
important to appreciate the advantages and potential risks of the method of anesthesia. Careful choice of the anesthetic technique must be selected for the type of surgery. Merging an inconsequentially invasive surgical procedure with a less invasive anesthetic technique, spinal anesthesia appears to additional improve the benefit of LC. Although the mentioned advantage, the use of spinal anesthesia for LC has still not gained popularity. Lately, few studies have emphasized the viability and security of performing LC under spinal anesthesia. This study determined to compare the postoperative effects between spinal anesthesia and general anesthesia in patients undergoing laparoscopic cholecystectomy.

\section{Methodology And Materials}

This comparative clinical study was conducted in in the Department of Anesthesia, Ashiyan Medical College Hospital, Barua Khilkhet, and Dhaka, Bangladesh during the period from January 2017 to December 2017. The aim of our study was to compare between Spinal Anaesthesia and General Anaesthesia for laparoscopic cholecystectomy in healthy patients. A total of 120 patients aged between 18-65 years of both sex with ASA Grade status I and II undergoing elective laparoscopic Cholecystectomy were selected for the study. After taking written informed consent from the study participants, we were elected 120 study subjects and divided into two groups; Group I $(n=60)$ received General Anaesthesia. And Group II $(n=60)$ received Spinal Anaesthesia. Elective laparoscopic Cholecystectomy procedure was taken. An intravenous line was secured in the right upper limb after taking the patients to the Operation Theater and infusion of $500 \mathrm{ml}$ of Ringer's Lactate solution started. Blood pressure cuff, ECG electrode and capnography monitor were applied. The initial pulse, blood pressure (BP), respiratory rate, ECG and end tidal CO2 (EtCO2) were noted. All the patients were premeditated with Inj. Glycopyrrolate 4 $\mathrm{mcg} / \mathrm{kg}$, Inj. Midazolam $0.02 \mathrm{mg} / \mathrm{kg}$ and Inj. Ondansetron $0.08 \mathrm{mg} / \mathrm{kg}$ intravenously (i.v.). In patients randomized for Spinal Anesthesia, the patient was first made to lie in supine position and all the monitors were attached. Oxygen was then administered through venturi mask at $31 /$ minute. Then the patient was made to lie in left lateral decubitus position. A 25-G Quincke spinal needle was introduced in subarachnoid space at L3-L4 interspace under all aseptic and antiseptic precautions. After confirming free flow of cerebrospinal fluid, $0.3 \mathrm{mg} / \mathrm{kg}$ of hyperbaric Bupivacaine $0.5 \%$ was injected intrathecally in cephalad direction. Then, after keeping the patient in the 150 Trendelenburg position for 5 minutes, the patient was again made to lie in a supine position. Approximately 10 minutes after intrathecal injection, the level of analgesia was checked. During this period, $500 \mathrm{ml}$ of $0.9 \%$ Ringer's Lactate was infused. A segmental sensory (pin-prick) block, extending between T4 and L5 dermatomes, was obtained without any respiratory distress. Laparoscopic cholecystectomy was performed using the same techniques in both the groups with standard for trocar insertion. After painting and draping, Inj. Bupivacaine plain $(0.2 \%) 10 \mathrm{ml}$ was injected subcostally under diaphragm equally on both sides in both the groups. Pneumoperitoneum was established by using the open (Hasson) technique with carbon dioxide at maximum intra-abdominal pressure of $12 \mathrm{~mm} \mathrm{Hg}$. Intraoperatively, the patients randomly allocated to general anesthesia group received fentanyl citrate 2 $\mu \mathrm{g} / \mathrm{kg}$ i.v. as an adjuvant while those allocated to spinal anesthesia group were given $25 \mu \mathrm{g}$ i.v. as bolus and when required. All the patients were monitored continuously both for clinical observation and noninvasive hemodynamic monitoring like electrocardiography, pulse, blood pressure, respiratory rate, pulse oximetry and EtCO2 which were recorded at 15-minute interval. Operative times as well as any intraoperative events such as shoulder pain, headache, nausea, and discomfort were recorded. Postoperative pain was assessed at 4, 8, 12 and 24 hours by using the Visual Analogue Scale (VAS) after completion of procedure. After collecting all data in a predesigned questionnaire, those were analyzed in Statistical Package for Social Sciences (SPSS) version 20. Other postoperative events either related to surgical or especially to anesthetic procedure, such as discomfort, nausea and vomiting, shoulder pain, urinary retention, pruritus, headache and other neurological sequel, were recorded.

\section{RESULTS}

Table-1: Demographic characteristics of the study participants $(n=120)$

\begin{tabular}{|l|c|c|c|c|}
\hline \multirow{2}{*}{ Characteristics of patients } & \multicolumn{2}{|c|}{ Group- I } & \multicolumn{2}{c|}{ Group-II } \\
\cline { 2 - 5 } & $\mathbf{N}$ & $\mathbf{\%}$ & $\mathbf{N}$ & $\mathbf{\%}$ \\
\hline Male & 42 & 70 & 38 & 63 \\
\hline Female & 18 & 30 & 22 & 37 \\
\hline Mean Age in Years & \multicolumn{2}{|c|}{36.67} & 34.58 \\
\hline Mean Operative Time(minutes) & \multicolumn{2}{|c|}{66.03} & 66.63 \\
\hline Average Hospital Stay(hours) & \multicolumn{2}{|c|}{48.33} & 36.53 \\
\hline
\end{tabular}


In this study majority patients $(70 \%$ and $63 \%$ in Group I and Group II respectively) were male and mean age was 36.67 in Group I, 34.58 in Group II.
Mean operative time (minutes) were 66.03 in Group I, 66.63 in Group II. Average hospital stay was 48.33 hours in Group I and 36.53 hours in Group II.

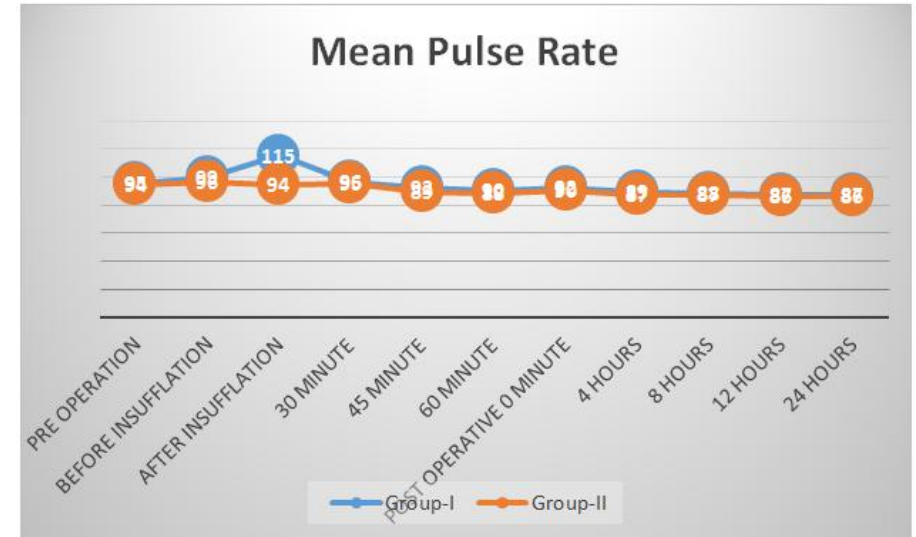

Fig-I: Perioperative comparison of mean pulse rate in Group-I and Group-II

Mean Pulse Rate (MPR) of Group I was 86 in pre-operative, 98 before insufflation, 114 after insufflation, 96 after $30 \mathrm{~min}$., 93 after $45 \mathrm{~min}$., 94 after $60 \mathrm{~min} ., 95$ in post-operative, 90 in $4 \mathrm{hrs}, 86$ in $8 \mathrm{hrs}, 82$ in $12 \mathrm{hrs}, 82$ in $24 \mathrm{hrs}$. Meanwhile, in Group II MPR was 86 in pre-operative, 88 before insufflation, 89 after insufflation, 90 after $30 \mathrm{~min} ., 91$ after $45 \mathrm{~min} ., 91$ after 60 min., 92 in post-operative, 88 in 4 hrs, 84 in 8 hrs, 80 in $12 \mathrm{hrs}, 80$ in $24 \mathrm{hrs}$.

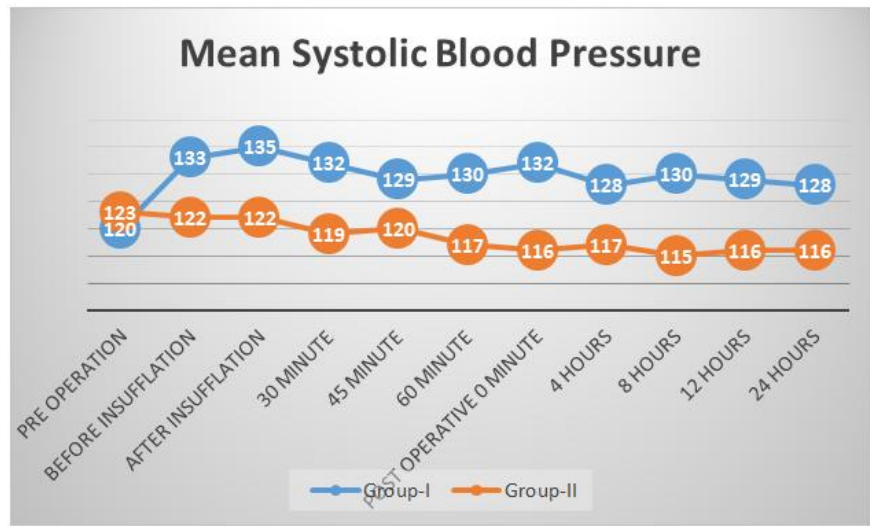

Fig-II: Perioperative comparison of mean systolic blood pressure in Group-I and Group-II

Mean Systolic BP(MSBP) was 120 in preoperative, 133 before insufflation, 135 after insufflation, 132 after 30 min., 128 after 45 min., 130 after 60 min., 132 in post-operative, 128 in 4 hrs, 130 in 8 hrs, 129 in $12 \mathrm{hrs}, 128$ in $24 \mathrm{hrs}$. Meanwhile, in Group II MSBP was 123 in pre-operative, 122 before insufflation, 122 after insufflation, 120 after $30 \mathrm{~min}$., 121 after $45 \mathrm{~min}$., 117 after $60 \mathrm{~min} ., 117$ in post-operative, 116 in $4 \mathrm{hrs}$, 120 in 8 hrs, 116 in $12 \mathrm{hrs}, 116$ in $24 \mathrm{hrs}$

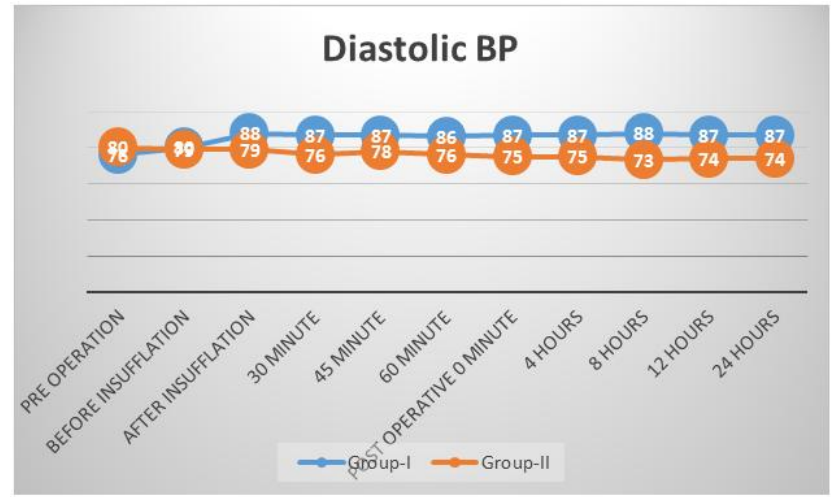

Fig-III: Perioperative Comparison of respiratory rate in Group-I and Group-II 
Mean Diastolic BP (MDBP) was 75 in preoperative, 81 before insufflation, 88 after insufflation, 87 after 30 min., 87 after 45 min., 88 after 60 min., 86 in post-operative, 87 in $4 \mathrm{hrs}, 86$ in $8 \mathrm{hrs}, 87$ in $12 \mathrm{hrs}$, 87 in 24 hrs. Meanwhile, in Group II MDBP was 80 in pre-operative, 80 before insufflation, 80 after insufflation, 78 after 30 min., 79 after 45 min., 78 after 60 min., 78 in post-operative, 76 in 4 hrs, 75 in 8 hrs, 74 in $12 \mathrm{hrs}, 73$ in $24 \mathrm{hrs}$.

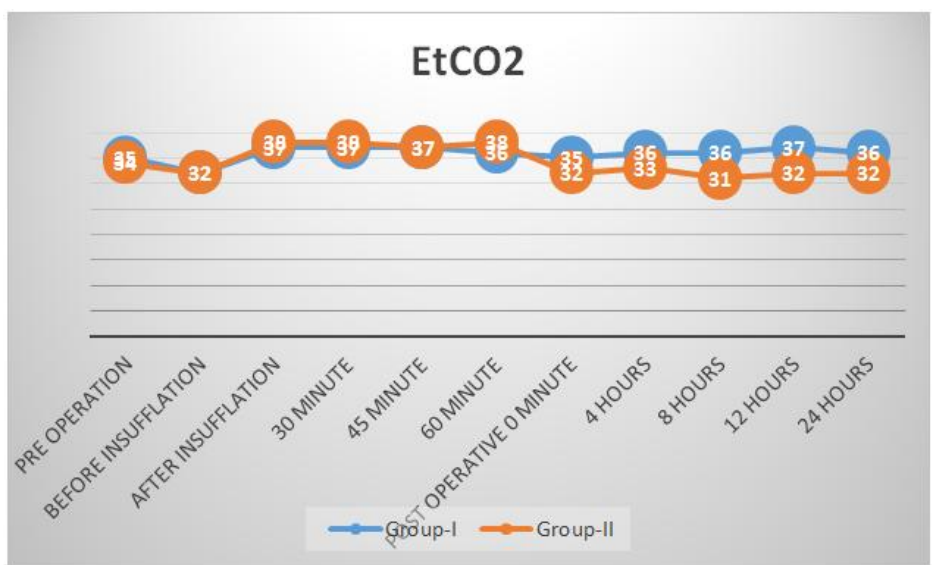

Fig-IV: Perioperative comparison of mean diastolic blood pressure in Group-I and Group-II

EtCO2 was 35 in pre-operative, 32 before insufflation, 37 after insufflation, 32 after 30 min., 32 after 45 min., 31 after 60 min., 35 in post-operative, 36 in $4 \mathrm{hrs}, 36$ in $8 \mathrm{hrs}, 37$ in $12 \mathrm{hrs}, 36$ in $24 \mathrm{hrs}$. Meanwhile, in Group II EtCO2 was 34 in pre-operative,
32 before insufflation, 38 after insufflation, 33 after 30 min., 32 after 45 min., 33 after 60 min., 32 in postoperative, 33 in 4 hrs, 31 in 8 hrs, 32 in 12 hrs, 32 in 24 hrs.

Table-1: At a glance Mean Pulse Rate (MPR), Mean Systolic BP (MSBP), Mean Diastolic BP MDBP \& EtCO2 (n=120)

\begin{tabular}{|c|c|c|c|c|c|c|c|c|c|c|c|c|}
\hline Sub. & Subject & $\begin{array}{c}\text { Pre- } \\
\text { operation }\end{array}$ & $\begin{array}{c}\text { Before } \\
\text { Insufflatio } \\
\mathbf{n}\end{array}$ & $\begin{array}{c}\text { After } \\
\text { Insufflation }\end{array}$ & $\begin{array}{c}\text { Aft. } \\
\text { 30 } \\
\text { min. }\end{array}$ & $\begin{array}{c}\text { Aft. } \\
45 \\
\text { min. }\end{array}$ & $\begin{array}{c}\text { Aft. } \\
60 \\
\text { min. }\end{array}$ & $\begin{array}{c}\text { Post- } \\
\text { Operative }\end{array}$ & $4 \mathrm{Hrs}$ & $8 \mathrm{Hrs}$ & $12 \mathrm{Hrs}$ & $24 \mathrm{Hrs}$ \\
\hline \multirow[t]{2}{*}{ MPR } & Group 1 & 86 & 98 & 114 & 96 & 93 & 94 & 95 & 90 & 86 & 82 & 82 \\
\hline & Group-2 & 86 & 88 & 89 & 90 & 91 & 91 & 92 & 88 & 84 & 80 & 80 \\
\hline \multirow[t]{2}{*}{ MSBP } & Group 1 & 120 & 133 & 135 & 132 & 128 & 130 & 132 & 128 & 130 & 129 & 128 \\
\hline & Group 2 & 123 & 122 & 122 & 120 & 121 & 117 & 117 & 116 & 120 & 116 & 116 \\
\hline \multirow[t]{2}{*}{ MDBP } & Group 1 & 75 & 81 & 88 & 87 & 87 & 88 & 86 & 87 & 86 & 87 & 87 \\
\hline & Group-2 & 80 & 80 & 80 & 78 & 79 & 78 & 78 & 76 & 75 & 74 & 73 \\
\hline \multirow[t]{2}{*}{$\mathrm{EtCO} 2$} & Group 1 & 35 & 32 & 37 & 32 & 32 & 31 & 35 & 36 & 36 & 37 & 36 \\
\hline & Group-2 & 34 & 32 & 38 & 33 & 32 & 33 & 32 & 33 & 31 & 32 & 32 \\
\hline
\end{tabular}

\section{DISCUSSION}

The surgical stress response remains an important feature of the laparoscopic approach, even though it is a less invasive procedure than open cholecystectomy [3-6]. In this study, we tried to compare Spinal Anaesthesia with General Anaesthesia for laparoscopic cholecystectomy in healthy patients. We have not only confirmed the probability of safely performing laparoscopic cholecystectomy under Spinal Anesthesia as the sole anesthetic method in our study, but also presented supremacy of Spinal Anesthesia in terms of enhanced postoperative pain control as associated to general anesthesia. Pain measured during the time in the postoperative period throughout the patients' hospital stay, which was meaningfully slighter in spinal Group I compared to Group II. It might be due to residual pain-relieving consequence of local anesthetic in subarachnoid space and reduction in distress owing to prevention of general anesthesia [7, 8]. In this study, in Group-II, hypotension (i.e. $>30 \%$ fall in BP) was noted in $30 \%$ cases, out of which mephentermine $6 \mathrm{mg}$ was given in only 2 cases and the rest were managed with i.v. fluids, while in Group-I, hypotension was noted in $10 \%$ cases and all of them were managed with i.v. fluids. Spinal anaesthesia tempts peripheral vasodilatation. Hereafter, laparoscopic procedure done under spinal anaesthesia may increase the risk of hypotension. In a study done by Sinha et al.[9] hypotension was observed in $20.5 \%$ cases. Diaphragmatic irritation was much less in the present study, as there was subcostal instillation of Inj. Bupivacaine plain $(0.2 \%) 10 \mathrm{ml}$ each on both sides just prior to notch. At times, this diaphragmatic irritation is so severe that there possibly will be alteration of the method to General Anesthesia. Using of low pressure pneumoperitoneum was satisfactory, specifically with spinal group, as Spinal Anesthesia reasons high level of motor, sensory and concerned barrier and thus good abdominal muscle reduction equally paralleled to General Anesthesia. In Group-I, the initial increase in 
pulse rate and BP after peritoneal insufflations are due to both mechanical and neurohumoral properties [10]. The reappearance of pulse rate and BP to normal baseline was regular. There was little variation in pulse and BP in Group I after peritoneal insufflation as spinal anesthesia is likely to decline the pulse and BP, although the neurohumoral and mechanical possessions of pneumoperitoneum incline to rise them. After more than a few minutes, the neurohumoral and mechanical properties are recompensed so that there is slight decrease in the pulse rate and BP. The reduction in pulse rate and BP in Group-II as equated to Group-I can be explained as as a result of decline in pain affected by residual analgesic consequence of local anesthetic in subarachnoid space. General anaesthetic is a choice of anaesthetic technique for laparoscopic procedures. Evidence based recent statistics suggest regional anaesthesia for laparoscopic cholecystectomy as a harmless, cost-effective and good postoperative pain control. But then there are fears linked to Spinal Anesthesia alike elevated intra-abdominal pressure consequential in regurgitation of gastric content. There is also a fear of hypotension throughout laparoscopic procedures completed under Spinal Anesthesia owing to the result of condensed intravenous return peripheral vasodilatation because of Spinal Anesthesia and also resulting in improved intra-abdominal pressure and inverted Trendelenburg position $[11,12]$.

\section{LIMITATIONS OF THE STUDY}

This was a clinical study in a single centre with small a sample size. So, the study results may not reflect the scenarios of the whole community.

\section{CONCLUSION AND \\ RECOMMENDATIONS}

Spinal Anaesthesia was observed to be better safety and sufficiency in patients of good health in the present study. It provides better post-operative pain regulator devoid of restraining the recovery as per our recommendation. Yet, there is limited number of evidence based data to support Spinal Anesthesia as the standard of care. A large prospective double-blind randomized controlled trial comparing Spinal Anesthesia and general anesthesia in Laparoscopic Cholecystectomy is required to recognize the finest technique.

Funding: No funding sources

Conflict of interest: None declared
Ethical approval: The study was approved by the Institutional Ethics Committee

\section{REFERENCES}

1. Bessa SS, Katri KM, Abdel-Salam WN, El-Kayal SA, Tawfik TA. Spinal versus general anesthesia for day-case laparoscopic cholecystectomy: A prospective randomized study. J Laparoendosc Adv Surg Tech. 2012; 22:550-555.

2. Keus F, De Jong JAF, Gooszen HG, Van Laarhoven CJHM. Laparoscopic versus open cholecystectomy for patients with symptomatic cholecystolithiasis. Cochrane Database Syst Rev. 2006; 4:CD006231.

3. Schauer PR, Sirinek KR: The laparoscopic approach reduces the endocrine response to elective cholecystectomy. Am Surg. 1995; 61: 106- 111.

4. Karayiannakis AJ, Makri GG, Mantzioca A. Systemic stress response after laparoscopic or open cholecystectomy: a randomized trial. $\mathrm{Br} J$ Surg. 1997; 84: $467-471$.

5. Dexter SP, Griffith JP, Grant PJ. Activation of coagulation and fibrinolysis in open and laparoscopic cholecystectomy. Surg Endosc. 1996; 10: 1069 - 1074 .

6. Donald RA, Perry EG, Wittert GA. The plasma ACTH, AVP, CRH and catecholamine responses to conventional and laparoscopic cholecystectomy. Clin Endocrinol (Oxf). 1993; 38: 609 - 615.

7. Tzovaras G, Fafoulakis F, Pratsas K, Georgopoulou S, Stamatiou G, Hatzitheofilou C. Spinal vs general anesthesia for laparoscopic cholecystectomy: Interim analysis of a controlled randomized trial. Arch Surg. 2008; 143:497-501.

8. Pharmacoeconomic comparison vs general anesthesia. Can J Anesth. 2001; 48:279-83.

9. Sinha R, Gurwara AK, Gupta SC. Laparoscopic cholecystectomy under spinal anaesthesia: A study of 3492 patients. J Laparoendosc Adv Surg Tech A. $2009 ; 19: 323-7$.

10. Aono H, Takeda A, Tarver S, Goto H. Stress responses in three different anesthetic techniques for carbon dioxide laparoscopic cholecystectomy. J Clin Anesth. 1998; 10:546-50.

11. CN Gutt, T Oniu, A Mehrabi, P Schemmer, A Kashfi, $\mathrm{T}$ Kraus. Circulatory and respiratory complications of carbon dioxide insufflation. Dig Surg. 2004; 21:95-105.

12. EA Hirvonen, EO Poikolainen, ME Pääkkönen, LS Nuutinen. The adverse hemodynamic effects of anesthesia, head-up tilt, and carbon dioxide pneumoperitoneum during laparoscopic cholecystectomy. Surg Endosc. 2004; 14:272-77. 